\title{
Effect of ambient concentration of carbon monoxide (CO) on the in-vehicle concentration of carbon monoxide in Chennai, India
}

\author{
J Aswin Giri, S Karthikeyan ${ }^{\dagger}$, M Gokul Raj \\ Centre for Environmental Studies, Anna University, Chennai-600025, India
}

\begin{abstract}
In this study, ambient concentration of Carbon monoxide (CO) was monitored at two locations, a signalized traffic intersection and at one kilometer away from the intersection in Chennai. The maximum CO concentration was found to be $38.82 \mathrm{mg} / \mathrm{m}^{3}$ and $1.15 \mathrm{mg} / \mathrm{m}^{3}$ at signalized traffic intersection and one kilometer away from the intersection, respectively. The $1 \mathrm{~h}$ average in-vehicle carbon monoxide concentration in cars during Air Conditioner (A/C)-ON recirculation mode, A/C-ON fresh air mode and windows open mode are $2.4 \mathrm{mg} / \mathrm{m}^{3}, 4 \mathrm{mg} / \mathrm{m}^{3}$ and $5.7 \mathrm{mg} / \mathrm{m}^{3}$, respectively. The dilution rates of CO in these modes were found to be $0.14 \mathrm{mg} / \mathrm{m}^{3} / \mathrm{min}, 0.51 \mathrm{mg} / \mathrm{m}^{3} / \mathrm{min}$ and $1.71 \mathrm{mg} / \mathrm{m}^{3} / \mathrm{min}$, respectively. The Root Mean Square Error (RMSE) for $\mathrm{A} / \mathrm{C}$ recirculation, $\mathrm{A} / \mathrm{C}$ fresh air, windows open modes in car and windows open in bus were $2.06,3.27,0.79$ and 1.82 , respectively. For short trips, $\mathrm{A} / \mathrm{C}$ - on recirculation mode was found to be suitable and continuous use of $\mathrm{A} / \mathrm{C}$ in longer trips led to accumulation of $\mathrm{CO}$. It is advisable to switch to either $\mathrm{A} / \mathrm{C}$ on Fresh air mode or windows open mode during longer trips to prevent accumulation of in-vehicle $\mathrm{CO}$.
\end{abstract}

Keywords: Carbon Monoxide, In-vehicle exposure, Traffic intersection, Ventilation setting

\section{Introduction}

Carbon monoxide (CO) is a colorless and odorless gas, has more affinity to hemoglobin, which increases carboxyhaemoglobin content in the blood. The increase in carboxyhemoglobin decreases the oxygen carrying capacity of blood and causes carbon monoxide poisoning, resulting in headache, nausea, dizziness and in extreme cases death. The emission of carbon-monoxide from idling vehicles at traffic intersections emit $45-55 \%$ more CO, compared to transit vehicles in roundabouts [1-5]. The fuel consumption increased by about $150 \%$ when accessories like air-conditioner was used during idling [6]. The total quantity of fuel wasted at five intersections was about $389.68 \mathrm{~L}$ of diesel and $810.38 \mathrm{~L}$ of petrol per day and the estimated monetary loss due to idling was ranging from Rs.3crore to 5crore /annum [2, 7-10].

The in-vehicle air is an extension of outdoor air, which infiltrates through ventilation settings, cracks and vents [11-13]. The in-vehicle $\mathrm{CO}$ is affected by outside sources and it reaches peak values when the surrounding vehicles are idling [14]. Thus, there is a possibility of in-vehicle CO build-up at traffic intersections. Irrespective of the age of the car, there was a high likelihood for self-pollution [15]. The car cabin acts as a sink during A/C ON-mode, which results in increase of in-vehicle CO by accumulation [16]. The overview of studies that have been conducted on in-vehicle CO is presented in Table S1.

This study has two parts, first part is the monitoring of ambient CO levels at a traffic intersection in Chennai along with fuel consumption during vehicle idling and the second part of the study includes effect of ambient $\mathrm{CO}$ on in-vehicle $\mathrm{CO}$ at the signalized traffic intersections and modeling of In-vehicle CO due to ambient CO using Principal Component Regression Analysis (PCRA).

\section{Material and Methods}

\subsection{Monitoring of $\mathrm{CO}$}

The ambient CO was monitored at a signalised traffic intersection of Vijayanagar, Velachery, Chennai which connects three main
This is an Open Access article distributed under the terms of the Creative Commons Attribution Non-Commercial License (http://creativecommons.org/licenses/by-nc/3.0/) which permits unrestricted non-commercial use, distribution, and reproduction in any medium, provided the original work is properly cited.

Copyright (C) 2021 Korean Society of Environmental Engineers
Received March 31, 2020 Accepted June 21, 2020

${ }^{\dagger}$ Corresponding author

Email: ksingaram@gmail.com

Tel: +91-9884612135

ORCID: 0000-0001-8087-0767 


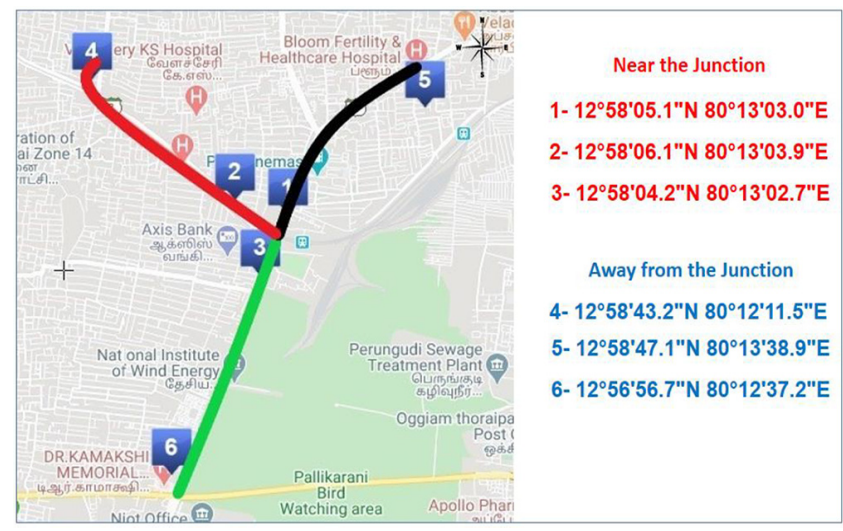

Fig. 1. Sampling locations at Velachery intersection.

arterial roads. The carbon monoxide was measured using a CO monitor (PGM5210 - IAQRAE, make: USA). It is a portable model, with data logging capability that uses an electrochemical senor to measure CO levels. The monitoring was carried out at three locations, near the intersection (L1, L2 and L3) and at $1 \mathrm{~km}$ away from the intersection (L4, L5 and L6) as shown in (Fig. 1). At each location, five sets of $8 \mathrm{~h}$ data were collected from 9 am to $5 \mathrm{pm}$.

The data were logged for every $30 \mathrm{~S}$. The concentration of carbon monoxide was monitored for each cycle of signal timing during which the vehicles were either in idling or moving with a minimum acceleration. The concentration of CO during idling of vehicles at traffic signal has been correlated with the amount of CO emission tested under idling condition for different types of vehicle.

Traffic volume was monitored at the intersection by video recording to determine the number of vehicles waiting during the red signal and to classify their type. The vehicles were categorised as two wheeler, three wheeler, four wheeler, buses and trucks.

The emission test was carried out for different types of vehicles to measure CO emission during idling condition. An AVL smoke meter, (make: Graz, Austria) for diesel vehicles and MARS meter (make: India) for petrol vehicles were used to test the CO emission during idling condition. Thirty seven (37) petrol vehicles and seventeen (17) diesel vehicles of different ages were tested in the study. The idling time of vehicles varied from $5 \mathrm{~min}$ to $20 \mathrm{~min}$. The loss of fuel was estimated as given in Eq. (1).

$$
\begin{aligned}
& \text { Amount of fuel wastage } \\
& \quad=\text { Count of idling Vehicles } \times \text { Red signals duration } \\
& \quad \times \text { Fuel consumption during idling }
\end{aligned}
$$

The estimated quantity of fuel consumed during idling of vehicle was correlated with the cost of fuel and energy to find the monetary loss and the energy loss.

\subsection{In-vehicle CO Monitoring}

The in-vehicle CO was measured in two modes of transportation viz., car and bus, in three routes of Chennai as shown in (Fig. 1) and a whole map along which the ambient $\mathrm{CO}$ were measured is depicted in the (Fig. S1), taking into account the waiting time at intersections and ventilation settings of vehicles.

The route 1 (R1) is of $16 \mathrm{~km}$ distance from Anna university to Shollinganallur, with 7 signalised traffic intersections, route 2 (R2) is of $13 \mathrm{~km}$ distance from Anna university to Porur with 8 signalised traffic intersections and route 3 (R3) is from Anna University to Avadi, having $30 \mathrm{~km}$ distance with 12 signalised traffic intersections. The in-vehicle CO and corresponding ambient $\mathrm{CO}$ were monitored simultaneously and continuously using two CO monitors during the following ventilation settings;

(i) 'A/C-ON recirculation mode', (In car, all the windows were closed and $\mathrm{A} / \mathrm{C}-\mathrm{ON}$ with recirculation of the inside air).

(ii) 'A/C-ON fresh air mode', (In car, all windows were closed with the A/C-ON drawing fresh air from outside).

(iii) 'Windows open mode', (In non- $\mathrm{A} / \mathrm{C}$ cars and Buses, all windows were down with fan switched off).

A/C-ON recirculation mode was carried out along R3 route. $\mathrm{A} / \mathrm{C}-\mathrm{ON}$ fresh air mode and windows open mode for cars were carried out along R2 route. Windows open mode for buses was done along the R1 route. The instrument for out-vehicle $\mathrm{CO}$ was placed outside the car near the wind shield. The experiment was conducted during the peak traffic hours, from 9.00 to $11.30 \mathrm{AM}$ in the morning and from 4.00 to $5.30 \mathrm{PM}$ in the evening from December 2018 to March 2019. The same car was used to keep the self-pollution constant but different buses of the same model were used due to lack of availability.

\subsection{Principal Component Regression}

Mass balance models were developed by [13, 24, 25], and statistical models were developed by [26] to identify the factors that contribute to individual exposure levels and of interrelations between those factors. Multivariate models have been developed as given by [23]. In this study, Principal Component Analysis (PCA) was done for the observations and then least square regression was carried out on the principal components obtained from PCA for the in-vehicle $\mathrm{CO}$ on various ventilation settings.

\section{Results and Discussion}

\subsection{Average CO Emissions at Different Locations and Different Modes of Transportation}

The $8 \mathrm{~h}$ average $\mathrm{CO}$ concentration measured at the study locations is given in the Fig. 2 .

The $8 \mathrm{~h}$ average concentration of CO at L1, L2 and L3, (which are nearer to the intersection) were $1.86,2.54$ and $2.87 \mathrm{mg} / \mathrm{m}^{3}$ respectively. The minimum and maximum value of $\mathrm{CO}$ concentration observed during the monitoring period was $0.92 \mathrm{mg} / \mathrm{m}^{3}$ and $38.82 \mathrm{mg} / \mathrm{m}^{3}$, respectively. The occurrence of peak value of CO concentration at the intersection was observed between 9.00 $\mathrm{AM}$ and 11.30 AM in the morning and between 4.00 PM and 5.00 $\mathrm{PM}$ in the evening. The percentage exceedance of the National 


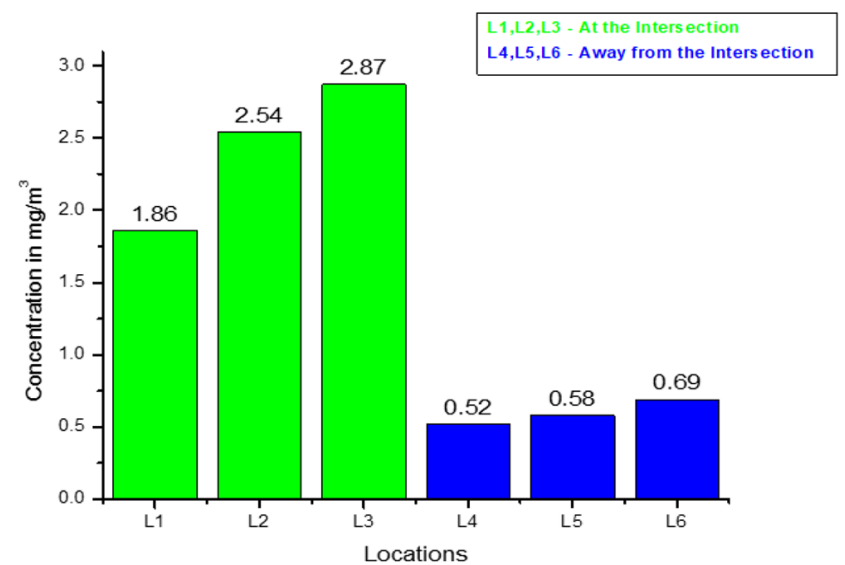

Fig. 2. $8 \mathrm{~h}$ average concentration of $\mathrm{CO}$ at the intersection and away from the intersection.

Ambient Air Quality Standards (NAAQS) value of $2.0 \mathrm{mg} / \mathrm{m}^{3}$ for $8 \mathrm{~h}$ duration was in the range from $3.85 \%$ to $64.06 \%$ at intersection. Similarly, the $8 \mathrm{~h}$ average concentration of CO at L4, L5 and L6, (which are $1 \mathrm{~km}$ away from the intersection) were $0.52,0.58$ and $0.69 \mathrm{mg} / \mathrm{m}^{3}$, respectively. At these locations, the minimum value of $\mathrm{CO}$ concentration observed during the monitoring period was $0.11 \mathrm{mg} / \mathrm{m}^{3}$ and the maximum value was about $1.15 \mathrm{mg} / \mathrm{m}^{3}$. A schematic representation of the Velachery intersection and the average percentage of various types of vehicles crossing the junction are represented in Fig. 3 (a) and (b), respectively.

The total number of vehicles recorded during the monitoring period was about 45,444. About 213 signal cycles was covered during the monitoring period of $8 \mathrm{~h}$ with the signal cycle timing of $135 \mathrm{~S}$ (2.25 $\mathrm{min})$.

It was found that, on an average $309.55 \mathrm{~L}$ of petrol and 84.67 $\mathrm{L}$ of diesel were wasted during idling of vehicles for a monitoring period of $8 \mathrm{~h}$, at signal intersections [2]. The monetary loss was found by multiplying fuel cost and fuel wasted due to idling.
The total cost spent on fuel, which was lost due to idling of vehicles at the intersection was estimated to be in the range of Rs.31,230/- to Rs.31,575/- for the monitoring period of $8 \mathrm{~h}$. If the loss was extrapolated to whole year for the above said duration, then around Rs.11.39 to Rs.11.52 million will be the loss incurred due to idling of vehicles at Vijayanagar intersection. The estimated value of total energy loss at intersection due to idling of vehicles for $1 \mathrm{~L}$ of fuel was $13617.8 \mathrm{MJ}$.

The average range of carbon monoxide emission rate during idling for different types of vehicles is given in Table S2.

The obtained emission rates were compared with secondary source [5] and it was observed that the obtained emission rates were much lower than the secondary data.

The mass of CO emitted by vehicles was determined by the formula given in Eq. (2).

$$
\text { Mass of } \mathrm{CO}(\mathrm{g})=
$$

No. of vehicles idling $\times$ idling time of vehicle $(S) \times$ Emission rate $\left(\frac{g}{s}\right)$

The CO emission rate and traffic volume were correlated along with the idling time to determine the total mass of carbon monoxide. The lowest and highest value of CO mass observed at the intersection for $8 \mathrm{~h}$ duration was $596.95 \mathrm{~g}$ and $1069.24 \mathrm{~g}$, respectively as given in Table S3.

\subsection{Effect of Ambient $\mathrm{CO}$ on In-vehicle CO}

\subsubsection{In-vehicle $\mathrm{CO}$ during $\mathrm{A} / \mathrm{C}$ ON Recirculation setting}

The minimum and maximum in-vehicle $\mathrm{CO}$ during $\mathrm{A} / \mathrm{C}-\mathrm{ON}$ Recirculation mode were $3.40 \mathrm{mg} / \mathrm{m}^{3}$ and $11.1 \mathrm{mg} / \mathrm{m}^{3}$, respectively as depicted in Fig. 4 (a). The mean value of in-vehicle CO was $7.15 \pm 2.17 \mathrm{mg} / \mathrm{m}^{3}$. The minimum in-vehicle CO was observed at the first intersection, whereas that of maximum was at the last intersection. It was also observed that the increase of in-vehicle CO concentration was steady with fewer spikes. Similar variation of in-vehicle CO concentration was measured by [13] along a highway. It is attributed to the tight closure of windows and absence of dilution in $\mathrm{A} / \mathrm{C}-\mathrm{ON}$ recirculation mode. When the
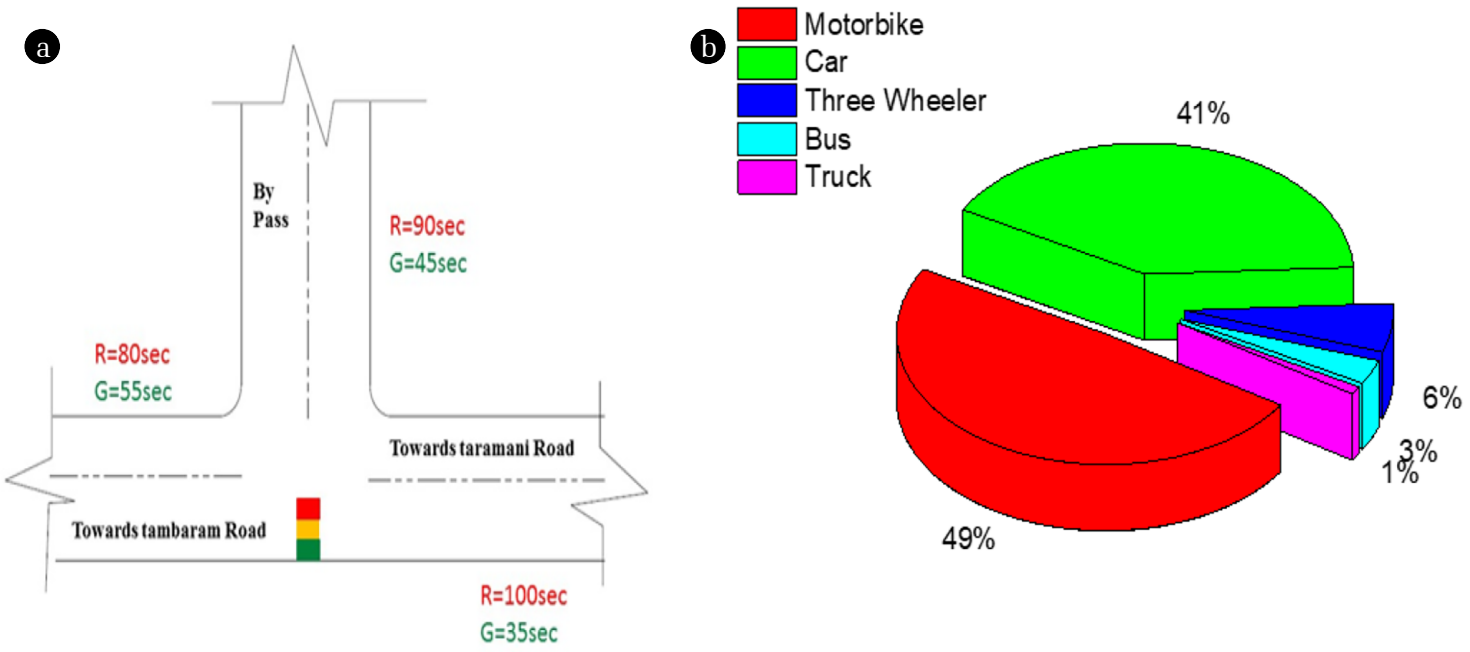

Fig. 3. (a) Schematic Representation of Velachery Intersection (b) Percentage of Vehicles Crossing the Intersection. 
car travels through consecutive traffic intersections and the time of travel increases, the in-vehicle CO accumulates steadily despite the fluctuations in the outdoor $\mathrm{CO}$ at intersections. The potential sources for the accumulation are ambient CO i.e. CO from other external activities and CO release from other surrounding vehicles and self-polluting activities such as smoking and incense sticks inside the vehicles also increases the pollutants level.

\subsubsection{In-vehicle $\mathrm{CO}$ during $\mathrm{A} / \mathrm{C}-\mathrm{ON}$ fresh air setting}

The average in-vehicle $\mathrm{CO}$ concentration during $\mathrm{A} / \mathrm{C}-\mathrm{ON}$ fresh air mode was $10.5 \pm 2.9 \mathrm{mg} / \mathrm{m}^{3}$. The maximum and minimum concentrations were $16 \mathrm{mg} / \mathrm{m}^{3}$ and $6.87 \mathrm{mg} / \mathrm{m}^{3}$, respectively. The in-vehicle CO concentration was highly fluctuating when compared with A/C-ON Recirculation mode, as depicted in Fig. 4 (b). As well as, the peak, minimum and average in-vehicle $\mathrm{CO}$ concentrations were also more than that of A/C-ON Recirculation mode, throughout the observation. This may be due to higher air exchange rate between the interior and the exterior environment during $\mathrm{A} / \mathrm{C}-\mathrm{ON}$ fresh air mode. This is concordant with the findings of [15], who stated that highest exposures can happen in 'A/C-ON fresh air' or 'windows open' ventilation setting. During the experiment it was found that the in-vehicle CO levels decreased as quickly as they increased, indicating the dilution of the cabin air.

\subsubsection{In-vehicle $\mathrm{CO}$ during windows open setting}

The fate of in-vehicle CO concentration in windows open mode was similar to that of $\mathrm{A} / \mathrm{C}-\mathrm{ON}$ fresh air mode as depicted in Fig. 4(c). The maximum, minimum and mean in-vehicle CO concentrations during windows open mode were $10.3 \mathrm{mg} / \mathrm{m}^{3}, 3.66 \mathrm{mg} / \mathrm{m}^{3}$ and $6.7 \pm 1.82 \mathrm{mg} / \mathrm{m}^{3}$ respectively. The fluctuation in the in-vehicle $\mathrm{CO}$ concentration was very high, while the car was moving from an intersection to another intersection, followed the profile of ambient CO concentration. During the experiment, it was observed that, when the vehicle was stationary, the in-vehicle CO concentration was very low but when the car starts moving at very low speeds, the CO levels increased. This is attributed to the natural air exchange between exterior and interior environment. However, it was contrary to the findings of [13], who observed that the in-vehicle $\mathrm{CO}$ followed the exterior CO levels even at stationary state.

\subsubsection{In-vehicle $\mathrm{CO}$ for non-air conditioned buses}

In the non- $\mathrm{A} / \mathrm{C}$ buses, the mean concentration of in-vehicle $\mathrm{CO}$ was $13.8 \pm 5.48 \mathrm{mg} / \mathrm{m}^{3}$. The maximum and minimum concentrations were $34.35 \mathrm{mg} / \mathrm{m}^{3}$ and $8 \mathrm{mg} / \mathrm{m}^{3}$, respectively which as represented in Fig. 4(d). The in-vehicle CO for buses followed the out-vehicle CO and the concentration decreased as soon as the bus left the intersection. Even though cars with windows open and non-air conditioned buses have the same natural ventilation setting, there was difference in the in-vehicle CO concentrations. This may be due to the different intake height of the vehicles as given by [27]. The intake height for bus is $1.8 \mathrm{~m}$ and for car is $0.9 \mathrm{~m}$.

\subsubsection{In-vehicle CO VS out-vehicle CO}

From Fig. 4 (a), we can observe the accumulation of in-vehicle $\mathrm{CO}$ and at some intersections, the in-vehicle $\mathrm{CO}$ concentration was higher than the out-vehicle CO due to internal pollution. It could be noted from Fig. 4 (b), the in-vehicle CO concentration of $\mathrm{A} / \mathrm{C}$
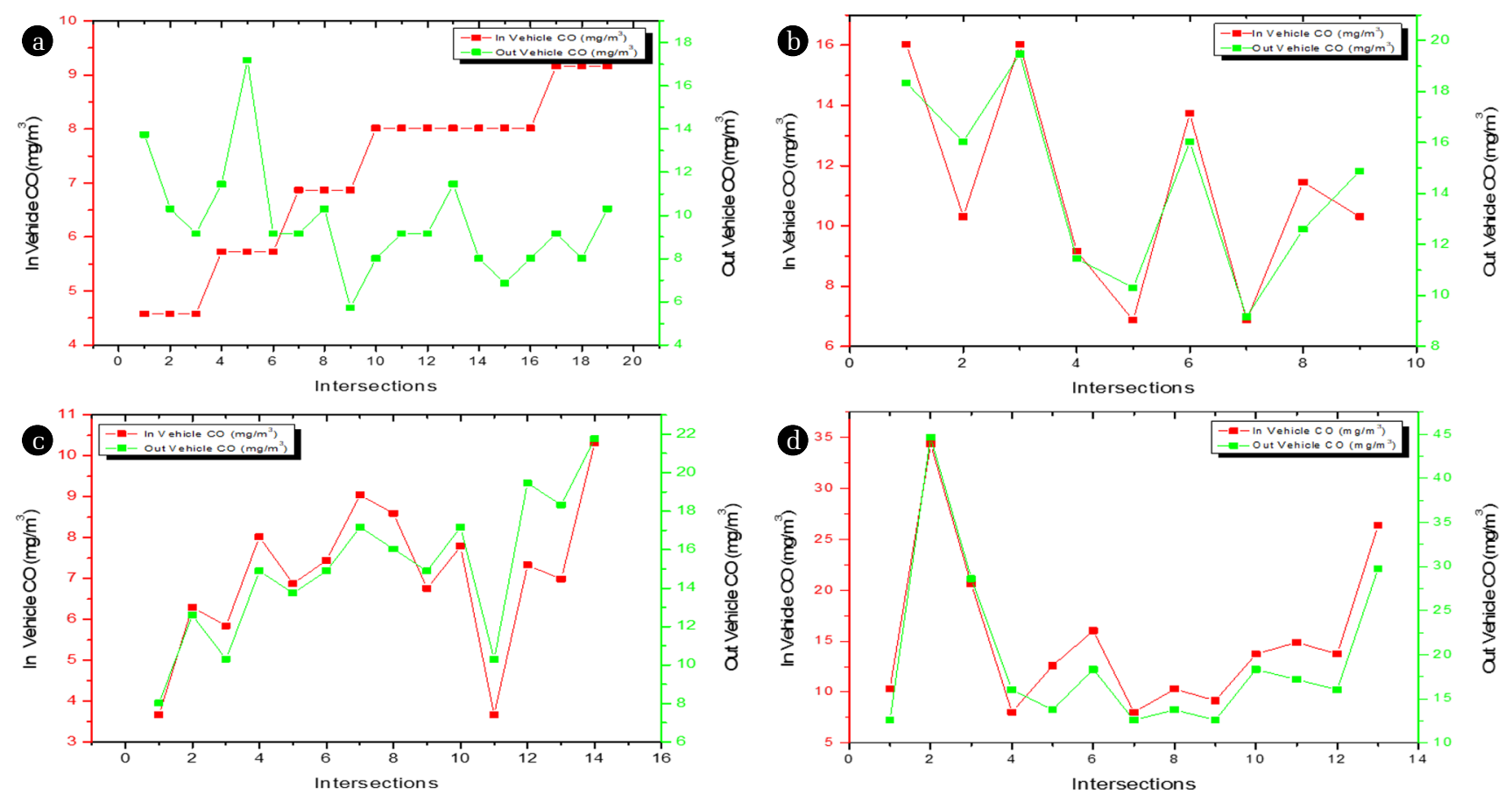

Fig. 4. Comparison of in-vehicle $\mathrm{CO}$ and out-vehicle $\mathrm{CO}$ for (a) Car - A/C ON recirculation, (b) Car - A/C ON fresh air recirculation, (c) Car - windows open, (d) Bus - windows open. 


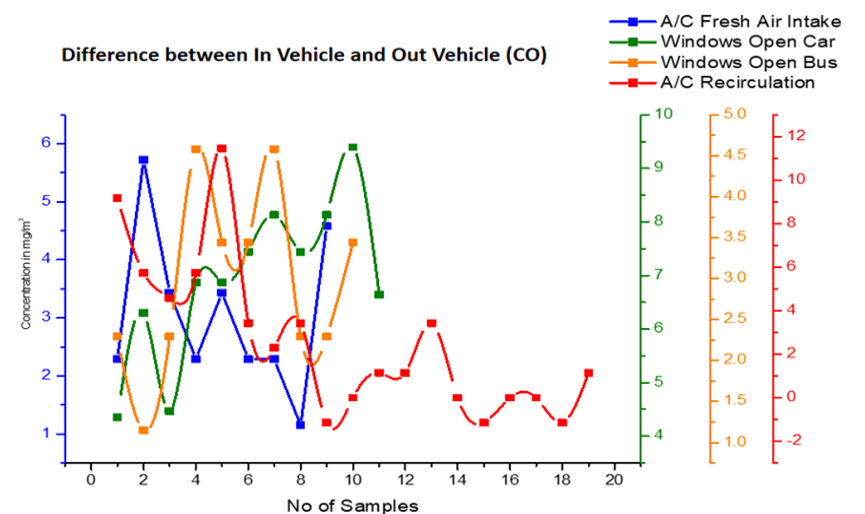

Fig. 5. Comparison of difference between in and out vehicle $\mathrm{CO}$ for different modes.

ON Fresh Air mode and the corresponding out-vehicle CO followed the similar kind of ridges and furrows pattern. It was due to the exterior and interior air exchange by the ventilation system of the vehicle. Though the profile of in-vehicle $\mathrm{CO}$ and out-vehicle CO is similar during windows open mode (Fig. 4 (c)), the difference between the concentrations of in-vehicle and out-vehicle $\mathrm{CO}$ is high. Unlike the A/C-ON Fresh Air mode, where the fresh air was drawn mechanically, air exchange due to natural ventilation occurred in windows open mode. The in-vehicle CO closely follows the out-vehicle CO in open buses as depicted in Fig. 4 (d). It may be due to the high intake position of the bus, where the CO levels are higher due to pollutant dispersion by aerodynamic drag as mentioned by [27].

The difference between in-vehicle CO concentration and out-vehicle CO concentration during various ventilation setting modes in the two different modes of transportation is depicted in the Fig. 5 below.

From the above figure we can see that for shorter duration in $\mathrm{A} / \mathrm{C}$ recirculation the difference between in and out vehicle $\mathrm{CO}$ is high but as the duration increases the difference decreases. $\mathrm{A} / \mathrm{C}$ fresh air and windows open-bus have lesser difference between in and out vehicle $\mathrm{CO}$ as compared to windows open-car. The increase in the shorter duration is attributed to the fact that, ignition of the vehicle leads to a sharp spurt of $\mathrm{CO}$, which decrease as the vehicle runs for a longer duration with $\mathrm{A} / \mathrm{C}-\mathrm{ON}$.

\subsection{Dilution Rate of In-vehicle CO for Various Ventilation Settings}

Dilution rate was found by measuring the rate of decrease of in-vehicle $\mathrm{CO}$ once the vehicle moved from the intersection. It was found that the dilution rate for $\mathrm{A} / \mathrm{C}-\mathrm{ON}$ recirculation mode, $\mathrm{A} / \mathrm{C}-\mathrm{ON}$ fresh air mode and windows open mode in car were $0.14 \mathrm{mg} / \mathrm{m}^{3} / \mathrm{min}$, $0.51 \mathrm{mg} / \mathrm{m}^{3} / \mathrm{min}$ and $1.71 \mathrm{mg} / \mathrm{m}^{3} / \mathrm{min}$, respectively. Since the car cabin acts as a buffer [15], dilution rate was less for A/C-ON recirculation mode. For A/C-ON Fresh air mode, the dilution rate was higher due to the mechanical ventilation which draws more fresh air into the cabin. For windows open mode in cars, the dilution rate was the highest due to natural ventilation provided by the wind. The variation of the dilution rate is explained by the air exchange rates compiled by [28] for stationary vehicles.

\subsection{Effects of Modes of $\mathrm{A} / \mathrm{C}$ Setting on Commuters' Exposure to $\mathrm{CO}$}

The average in-vehicle CO per hour of travel in car for different ventilation modes was estimated in this study. If $\mathrm{A} / \mathrm{C}-\mathrm{ON}$ recirculation mode is used for $1 \mathrm{~h}$ of travel, then the passenger will be exposed to an average of $2.4 \mathrm{mg} / \mathrm{m}^{3}$ of in-vehicle CO, whereas, in $\mathrm{A} / \mathrm{C}-\mathrm{ON}$ fresh air mode, the average $1 \mathrm{~h}$ exposure is $4 \mathrm{mg} / \mathrm{m}^{3}$. In Windows open mode, the average $1 \mathrm{~h}$ travel exposure is 5.7 $\mathrm{mg} / \mathrm{m}^{3}$. Even though $\mathrm{A} / \mathrm{C}$ recirculation mode has the least exposure, it is only applicable during the initial $1 \mathrm{~h}$ period. Since the in-vehicle $\mathrm{CO}$ tends to accumulate during $\mathrm{A} / \mathrm{C}-\mathrm{ON}$ recirculation mode, the CO levels increase as the travel time increases.

\subsection{Correlation Analysis}

For A/C-ON with recirculation setting, correlation coefficient between in-vehicle CO and out-vehicle CO was -0.4 and correlation coefficient between in-vehicle CO and waiting time was -0.18 as shown in Fig. 6 (a) and Fig. 7(a). The out-vehicle CO shows a moderate negative correlation with in-vehicle $\mathrm{CO}$ since the air exchange rate is very low. The waiting time has a weak negative correlation to in-vehicle CO. Since the in-vehicle CO for recirculation mode increases by accumulation, the regression plot does not represent the effect of waiting time on in-vehicle CO properly. The initial in-vehicle $\mathrm{CO}$ and the total usage time of $\mathrm{A} / \mathrm{C}-\mathrm{ON}$ recirculation mode may represent the accumulation more accurately.

For A/C-ON with fresh air setting, correlation coefficient between in-vehicle CO and out-vehicle CO was 0.82 and correlation coefficient between in-vehicle $\mathrm{CO}$ and waiting time was 0.49 as shown in Fig. 6 (b) and Fig. 7 (b). The out-vehicle CO shows a strong positive correlation with in-vehicle $\mathrm{CO}$, whereas the waiting time has a weak positive correlation to in-vehicle $\mathrm{CO}$, which may be due to the large variation between peak and minimum values.

For windows open setting, correlation coefficient between in-vehicle CO and out-vehicle CO was 0.407 and correlation coefficient between in-vehicle $\mathrm{CO}$ and waiting time was -0.081 as shown in Fig. 6 (c) and Fig. 7 (c). The out-vehicle CO shows a moderate positive correlation with in-vehicle $\mathrm{CO}$ whereas; the waiting time has a weak negative correlation to in-vehicle CO, which may be due to the natural ventilation.

For non-air conditioned bus, correlation coefficient between in-vehicle $\mathrm{CO}$ and out-vehicle $\mathrm{CO}$ was 0.966 and correlation coefficient between in-vehicle $\mathrm{CO}$ and waiting time was 0.08 as shown in Fig. 6 (d) and Fig. 7 (d). The out-vehicle CO correlates positively with in-vehicle CO whereas the waiting time has no correlation to in-vehicle $\mathrm{CO}$.

\subsection{Principal Component Regression Model}

Four models were developed for A/C-ON recirculation, A/C-ON fresh air and windows open setting for cars and one model for non- $\mathrm{A} / \mathrm{C}$ bus. The variables used for the model were waiting time, initial in-vehicle $\mathrm{CO}$, and out-vehicle $\mathrm{CO}$. For A/C-ON recirculation mode, additionally the total usage time of 'A/C recirculation' was used as a variable since the in-vehicle $\mathrm{CO}$ for this mode increases by accumulation. 

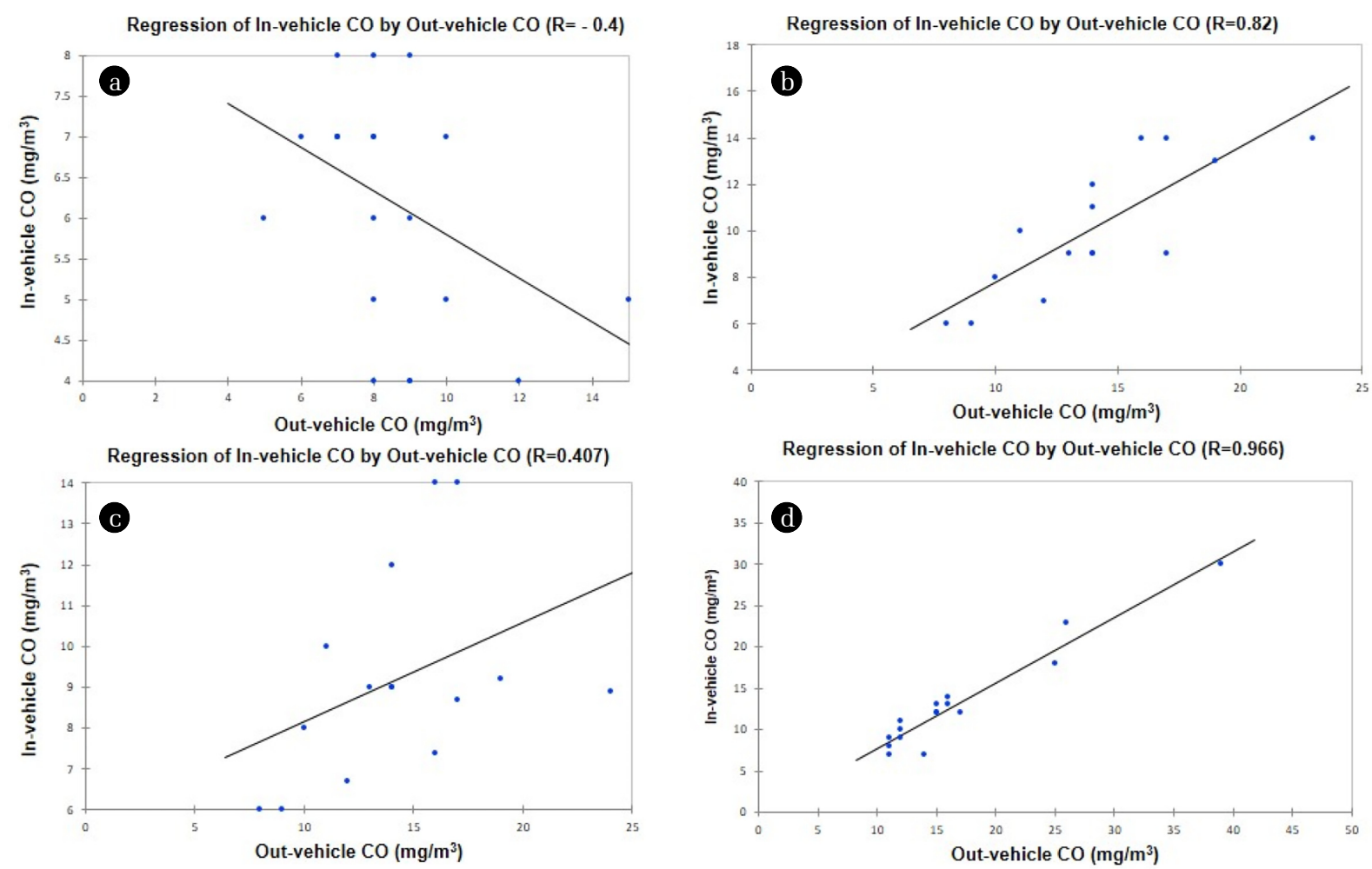

Fig. 6. Regression plot of in-vehicle CO by out-vehicle CO for (a) A/C on recirculation, (b) A/C on fresh air, (c) Windows open, (d) Non-Air conditioned bus.
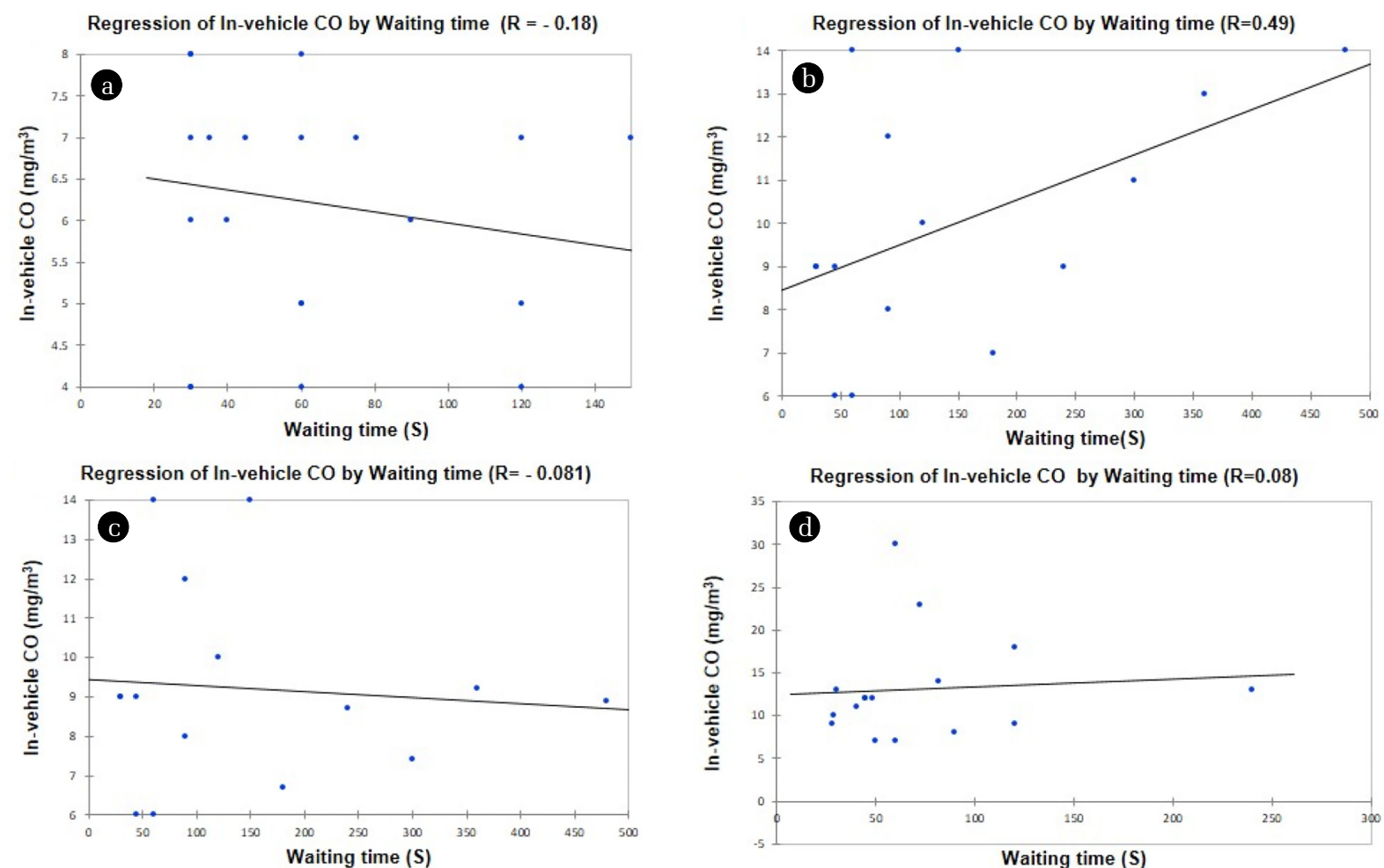

Fig. 7. Regression plot of in-vehicle CO by waiting time for (a) AVC on recirculation, (b) AVC on fresh air, (c) Windows ope,n (d) Non-Air conditioned bus. 
The equation obtained by PCRM for $\mathrm{A} / \mathrm{C}$ on recirculation, $\mathrm{A} / \mathrm{C}$ on fresh air and windows open setting for cars and bus are as given in the Eq. (3), (4), (5) and (6), respectively.

$$
\begin{gathered}
\text { In Vehicle CO }=0.122+(0.137 \times A)+(0.878 \times B)- \\
(0.0184 \times C)+(0.034 \times D) \\
\text { In Vehicle } C O=0.392-(0.0118 \times A)- \\
(0.18 \times B)+(0.95 \times C) \\
\text { In Vehicle CO }=0.149+(0.3353 \times A)+ \\
(0.336 \times B)+(0.3135 \times C) \\
\text { In Vehicle CO }=0.357-(0.0119 \times A)+(0.83 \times C)
\end{gathered}
$$

Where, A - Waiting time; B - Initial in-vehicle CO; C- Final out-vehicle CO; D - Total time travelled with A/C-ON

The Root Mean Square Error (RMSE) for A/C recirculation, A/C fresh air, windows open and bus models were 2.06, 3.27, 0.79 and 1.82, respectively. The RMSE values obtained are very high and incorporating the effect of air exchange rates and meteorology will reduce the error.

\section{Conclusions}

The ambient concentration of $\mathrm{CO}$ at $1 \mathrm{~km}$ away from a traffic intersection was about $74 \%$ lesser than the CO concentration at the intersection. When about 45,400 vehicles are passing through a traffic intersection in $8 \mathrm{~h}$, wasted an average of $310 \mathrm{~L}$ of petrol and $84 \mathrm{~L}$ of diesel due to idling at intersection. The monetary loss due to the fuel wasted in the above said condition was predicted to be about Rs.31, 000/-.

$\mathrm{A} / \mathrm{C}$ setting mode in vehicles influences the in-cabin air quality significantly. The in-vehicle CO concentration accumulated within the vehicle during $\mathrm{A} / \mathrm{C}-\mathrm{ON}$ recirculation mode. The car cabin acted as a buffer and continuous use of this setting resulted in high in-vehicle CO as its dilution rate was low. The in-vehicle CO in A/C-ON fresh air mode was in proportion to the out vehicle CO. The in-vehicle $\mathrm{CO}$ was higher at intersection due to higher outdoor $\mathrm{CO}$ and decreased once the car leaves the intersection. In vehicle $\mathrm{CO}$ in the windows open mode also follows the out-vehicle $\mathrm{CO}$, with the only difference that it is dependent on natural ventilation. The dilution rate of in-vehicle $\mathrm{CO}$ was in the order of AC-ON recirculation mode $<$ AC-ON fresh air mode $<$ windows open mode. The dilution rate of in-vehicle CO during $\mathrm{A} / \mathrm{C}-\mathrm{ON}$ fresh air mode was about 3.5 times higher than $\mathrm{A} / \mathrm{C}-\mathrm{ON}$ recirculation mode and about 3.5 times lesser than windows open mode. The hourly exposure of in-vehicle CO by the commuter was in the order of AC-ON recirculation mode $<$ AC-ON fresh air mode $<$ windows open mode. The hourly exposure of in-vehicle CO during A/C-ON fresh air mode was about 1.5 times higher than A/C-ON recirculation mode and about 1.5 times lesser than windows open mode. However, the exposure to in-vehicle $\mathrm{CO}$ was low in the AC-ON recirculation mode only during the beginning of travel. The Root Mean Square Error (RMSE) for A/C recirculation, A/C fresh air, windows open and bus models were 2.06, 3.27, 0.79 and 1.82 , respectively.

Therefore, from this study, it is recommended to keep A/C-ON recirculation mode for short trips and switch to either A/C-ON fresh air mode or windows open mode during long travels.

\section{Author Contributions}

J.A.G. (Post Graduate Student) conducted all the field works, experiments and developed the models, Dr. S.K. (Associate Professor) Supervised and mentored the overall work and M.G.R. (Ph.D. Student) conducted the field work and jointly wrote the manuscript.

\section{References}

1. McCormick RL, Graboski MS, Alleman TL, Yanowitz J. Idle emissions from heavy-duty diesel and natural gas vehicles at high altitude. J. Air Waste Manag. Assoc. 2000;50-11:1992-1998.

2. Tiwari KP. Fuel Wastage \& Emission Due To Idling of Vehicles At Road Traffic Signals. Int. J. Res. Eng. Technol. 2013;02-10:43-53.

3. Gastaldi M, Meneguzzer C, Rossi R, Della Lucia L, Gecchele G. Evaluation of air pollution impacts of a signal control to roundabout conversion using microsimulation. Transp. Res. Procedia. 2014;3:1031-1040.

4. Boubaker S, Rehimi F, Kalboussi A. Impact of intersection type and a vehicular fleet's hybridization level on energy consumption and emissions. J. Traffic Transp. Eng. 2016;3:253-261.

5. Tang TQ, Yi ZY, Lin QF. Effects of signal light on the fuel consumption and emissions under car-following model. Phys. A Stat. Mech. its Appl.2017;469:200-205.

6. Rahman Khan AS et al. Idle emissions from heavy-duty diesel vehicles: Review and Recent Data. J. Air Waste Manag. Assoc. 2006;56:1404-1419.

7. Sarkar S. Delay, fuel loss and noise pollution during idling of vehicles at signalized intersection in Agartala city. India. Environ. Res. 2012;2-6:8-15.

8. Bhandari K, Parida P, Singh P. Estimation of Carbon Footprint of Fuel Loss Due to Idling of Vehicles at Signalised Intersection in Delhi.Procedia Soc. Behav. Sci. 2013;104:1168-1177.

9. Sekhar CR, Raj P, Parida P, Gangopadhyay S. Estimation of Delay and Fuel Loss during Idling of Vehicles at Signalised Intersection in Ahmedabad. Procedia Soc. Behav. Sci. 2013;104: 1178-1187.

10. Rahman SMA, Masjuki HH, Kalam MA, Abedin MJ, Sanjid A, Sajjad A. Impact of idling on fuel consumption and exhaust emissions and available idle-reduction technologies for diesel vehicles - A review. Energy Convers. Manag. 2013;74:171-182.

11. Chan LY, Lau WL, Zou SC, Cao ZX, Lai SC. Exposure level of carbon monoxide and respirable suspended particulate in public transportation modes while commuting in urban area of Guangzhou , China. Atmos. Environ. 2002;36:5831-5840.

12. Chan AT, Chung MW. Indoor-outdoor air quality relationships in vehicle: Effect of driving environment and ventilation modes. Atmos. Environ. 2003;37:3795-3808.

13. Abi-Esber L, El-Fadel M. Indoor to outdoor air quality associa- 
tions with self-pollution implications inside passenger car cabins. Atmos. Environ. 2013;81:450-463.

14. Abi-Esber L, El-Fadel M, Nuwayhid I, Saliba M. The effect of different ventilation modes on in-vehicle carbon monoxide exposure. Atmos. Environ. 2007;41-17:3644-3657.

15. Leavey A, Reed N, Patel S, Bradley K, Kulkarni P, Biswas P. Comparing on-road real-time simultaneous in-cabin and outdoor particulate and gaseous concentrations for a range of ventilation scenarios. Atmos. Environ. 2017;166:130-141.

16. Alm S, Jantunen MJ, Vartiainen M. Urban commuter exposure to particle matter and carbon monoxide inside an automobile. J. Expo. Anal. Environ. Epidemiol.1999;3:237-244.

17. Clifford MJ, Clarke R, Riffat SB. Drivers Exposure To Carbon Monoxide. Atmos. Environ. 1997;31-7:1003-1009.

18. Clifford MJ, Clarke R, Riffat SB. Local aspects of vehicular pollution. Atmos. Environ. 1997;31-2:271-276.

19. Alm S, Jantunen MJ, Vartiainen M. Urban commuter exposure to particle matter and carbon monoxide inside an automobile. J. Expo. Anal. Environ. Epidemiol. 1999;9-3:237-244.

20. Zagury E, Le Moullec Y, Momas I. Exposure of Paris taxi drivers to automobile air pollutants within their vehicles. Occup. Environ. Med. 2000;57-06:406-410.

21. Chan MY. Commuters' exposure to carbon monoxide and carbon dioxide in air-conditioned buses in Hong Kong. Indoor Built Environ. 2005;14-05:397-403.
22. Both AF, Westerdahl D, Fruin S, Haryanto B, Marshall JD. Exposure to carbon monoxide, fine particle mass, and ultrafine particle number in Jakarta, Indonesia: Effect of commute mode. Sci. Total Environ. 2013;443:965-972.

23. Alameddine I, Abi-Esber L, Bou-Zeid E, Hatzopoulou M, El-Fadel M. Operational and environmental determinants of in-vehicle CO and PM 2.5 exposure. Sci. Total Environ. 2016;551 $-552: 42-50$.

24. Ott W, Switzer P, Willits N. Carbon monoxide exposures inside an automobile traveling on an urban arterial highway. J. Air Waste Manag. Assoc. 1994;44:1010-1018.

25. Heinsohn RJ, O'Donnell PEWR, Tao J. Automobile passenger compartment ventilation. ASHRAE Transactions.1993;99: 3669-3681.

26. Flachsbart PG. Models of exposure to carbon monoxide inside a vehicle on a Honolulu highway. J. Expo. Anal. Environ. Epidemiol. 1999;9-3:245-260.

27. Chan LY, Lau WL, Zou SC, Cao ZX, Lai SC. Exposure level of carbon monoxide and respirable suspended particulate in public transportation modes while commuting in urban area of Guangzhou, China. Atmos. Environ. 2002;36:5831-5840.

28. El-Fadel M, Abi-Esber L. In-Vehicle Exposure to Carbon Monoxide Emissions from Vehicular Exhaust: A Critical Review. Crit. Rev. Environ. Sci. Technol. 2009;39:39-89. 